\title{
A sinistra emergência do invisível: trabalhadores terceirizados e a crise da Uerj
}

\author{
Leila Braile, texto* \\ Guilherme Schneider** e Sérgio Franklin***, fotografias
}

Certa vez, Augusto Boal, criador do Teatro do Oprimido, ao lembrar o depoimento de uma das mulheres participantes do grupo de T.O. "Marias do Brasil", disse, emocionado, que uma das heranças mais importantes daquela experiência dramatúrgica, ao mesmo tempo política e terapêutica, era o de dar visibilidade àquelas trabalhadoras que, no ordinário dos dias, circulam como sombras pelas casas das famílias brasileiras.

Boal fazia, então, em um primeiro plano, referência a uma visibilidade literal, pois o grupo de teatro, formado essencialmente por empregadas domésticas, acabara de se apresentar em um palco iluminado e, em contraste, na penumbra da plateia, além dos familiares, amigos e com-

\footnotetext{
* Produtora Editorial da Assessoria de Comunicação da Associação de Docentes da Uerj. Correspondência: Universidade do Estado do Rio de Janeiro (UERJ). Rua São Francisco Xavier, 524 - 1º andar - Bloco D - Sala 1028 - Maracanã, Rio de Janeiro/RJ. CEP: 20550-013. Email:<leilabraile@gmail.com>.

** Jornalista da Assessoria de Comunicação da Associação de Docentes da Uerj. Correspondência: Universidade do Estado do Rio de Janeiro (UERJ). Rua São Francisco Xavier, 524 - 1ํandar - Bloco D - Sala 1028 - Maracanã, Rio de Janeiro/RJ. CEP: 20550-013. Email:<assessoriadeimprensa@asduerj.org.br>.

*** Jornalista da Assessoria de Comunicação da Associação de Docentes da Uerj. Correspondência: Universidade do Estado do Rio de Janeiro (UERJ). Rua São Francisco Xavier, 524 - 1ํo andar - Bloco D - Sala 1028 - Maracanã, Rio de Janeiro/RJ. CEP: 20550-013. Email:<assessoriadeimprensa@asduerj.org.br>.
} 


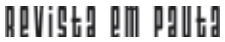

\} A SINISTRA EMERGÊNCIA DO INVISÍIVEL - BRAILE, L.; SCHNEIDER, G.; FRANKLIN, S. \}

DOI: $10.12957 /$ REP.2016.27868

panheiros de militância, lá estavam alguns dos patrões daquelas mulheres, na situação, possivelmente incomum, de considerá-las para além de suas funcionalidades ou de, pela primeira vez, vê-las simplesmente.

Assim, o artífice do teatro do oprimido lembrava, é certo, os efeitos emocionais da experiência de ser visto, quando, para alguém, ser visto é um fato inusitado - o que, evidentemente, não é pouco -, mas, acima de tudo, sublinhava, como consequência deste impacto psíquico, a viagem sem volta de se passar a ter um corpo humano, um tempo humano e um lugar humano para, finalmente, existir e confrontar-se com a alienação.

A memória deste episódio não é enfeite literário. No mundo inteiro, a marca moral da financeirização do trabalho tem sido a progressiva invisibilização do trabalhador. Quanto mais precárias são as relações laborais, maior é o apagamento dos traços de intencionalidade e sentido do trabalho. Mas algo de importante sai do lugar quando a engrenagem que mobiliza essa massa surda tangencia seus ciclos de crise. No Estado do Rio de Janeiro não tem sido diferente. Ao contrário, os serviços públicos em geral e a Universidade do Estado do Rio de Janeiro em particular são, há um tempo já bastante inaceitável, o laboratório de ensaio para a desarticulação do estado como entidade garantidora de direitos.

Desse processo há muitas e devastadoras consequências para todos, mas, principalmente, como sempre, para os trabalhadores que ocupam o chão da pirâmide socioeconômica. Um cenário que se sintetiza na figura do trabalhador terceirizado. Na Uerj, sem os seus salários mínimos, sem condições de trabalho e sem saída, a maioria, por um certo tempo, só comeu o pão que a solidariedade pôde arrecadar. Houve sinistros relatos de fome e despejo. No fim, abriu-se a porta da rua que dá acesso aos trens da Central. Todos demitidos sumariamente. Que procurassem seus direitos na Justiça, mas ninguém sabia onde era isso!

Muitíssimo ocupados com nossas aulas, bancas, Lattes, artigos, laboratórios, etc, por muito tempo, só havíamos ouvido falar "dessa gente" ocasionalmente... Os mais sensíveis talvez já tivessem visto algo daquele exército manso cor de cinza e cabeça baixa. Mas fomos obrigados a ver. De repente, não havia mais o elevador que sempre andou sozinho. Os banheiros autolimpantes entupiam. As lixeiras, sempre tão bem-comportadas, agora vomitavam nossos restos. Um estranho arquiteto erguia sobremuros de plástico negro ao nosso redor. O que foi feito dos jardins, dos peixes, dos patos? Morreram de saudades daquelas mãos pobres, sem saber o que era classe social. A garrafa de café ficou vazia e tudo o mais sabia a náusea e tumulto. Era impossível não ver.

Em uma primavera improvável, ipês floresciam impávidos, cheios de tédio e indiferença. Da forma mais dura possível, fomos lançados contra um mar revolto. Porém, forjada no fermento de nossas batalhas cotidianas, nossa fortaleza ou nossa simples teimosia de marujos nos tem afastado o desalento. E é por isso que a Uerj, como os ipês, ainda resiste. 


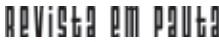

\} A SINISTRA EMERGÊNCIA DO INVISÍVEL - BRAILE, L.; SCHNEIDER, G.; FRANKLIN, S. \}

DOI: $10.12957 /$ REP. 2016.27868

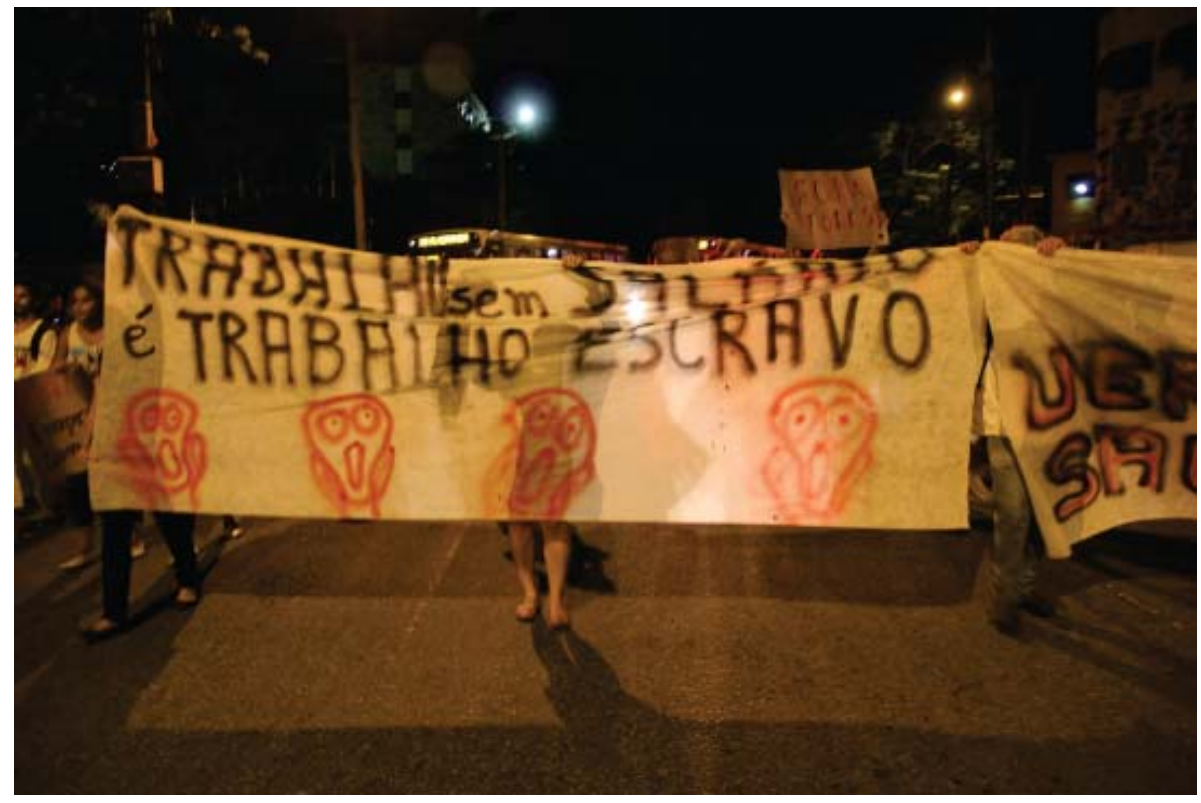

Ato público em defesa dos trabalhadores terceirizados da Uerj (Arquivo Asduerj)

EM PAUTA, Rio de Janeiro - $2^{\circ}$ Semestre de 2016 - n. 38, v. 14, p. 364 - 383 


\section{Revigta dII pallt}

\} A SINISTRA EMERGÊNCIA DO INVISÍIVEL - BRAILE, L.; SCHNEIDER, G.; FRANKLIN, S. \}

DOI: $10.12957 /$ REP.2016.27868

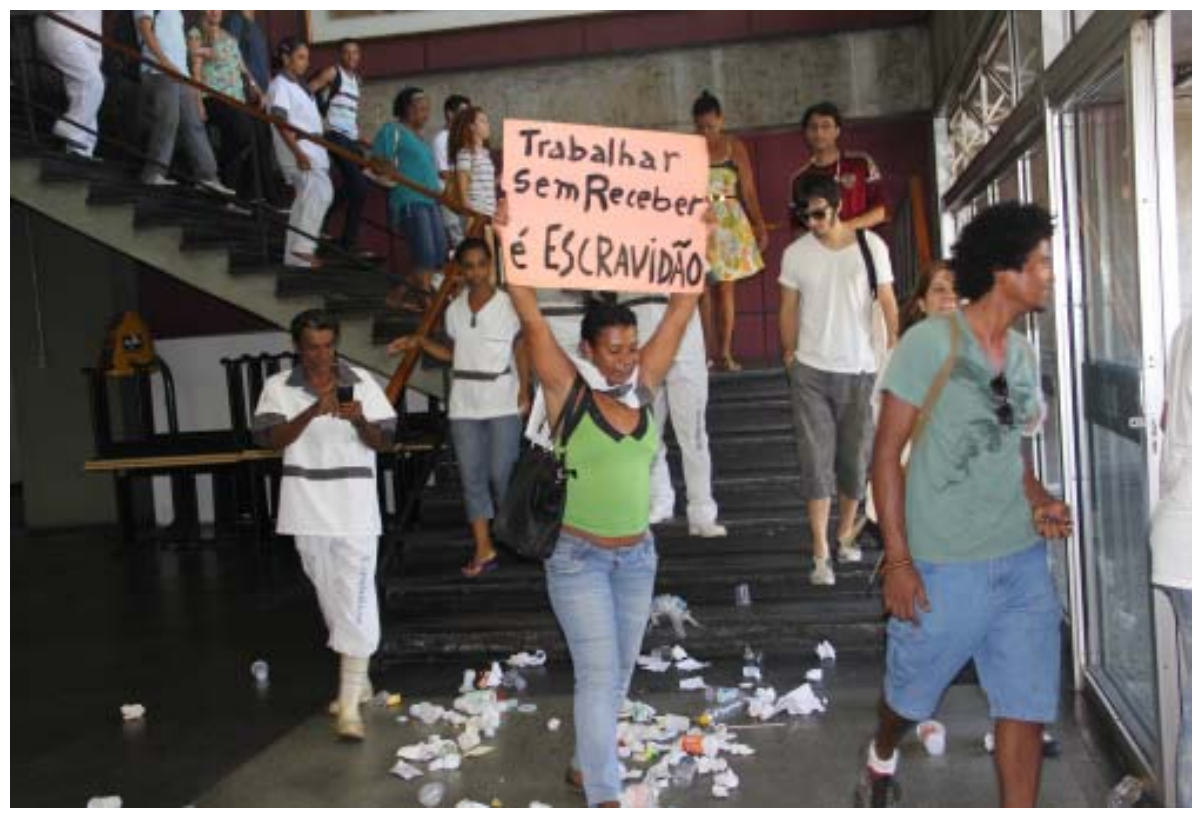

Trabalhadores terceirizados da Uerj reivindicam o pagamento de salários (Arquivo Asduerj) 


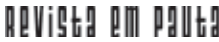

\} A SINISTRA EMERGÊNCIA DO INVISÍVEL - BRAILE, L.; SCHNEIDER, G.; FRANKLIN, S. \}

DOI: $10.12957 /$ REP. 2016.27868

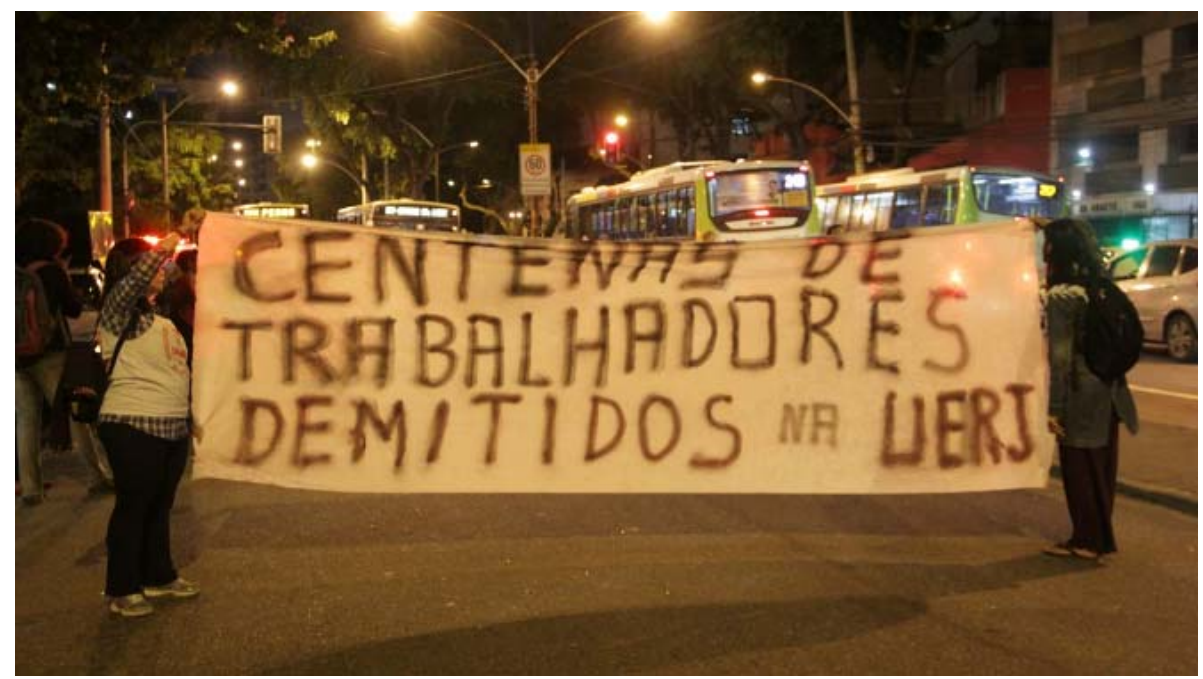

Ato público contra a demissão sumária de trabalhadores terceirizados da Uerj (Arquivo Asduerj) 


\section{Revigta dII pallt}

\} A SINISTRA EMERGÊNCIA DO INVISÍIVEL - BRAILE, L.; SCHNEIDER, G.; FRANKLIN, S. \}

DOI: $10.12957 /$ REP.2016.27868

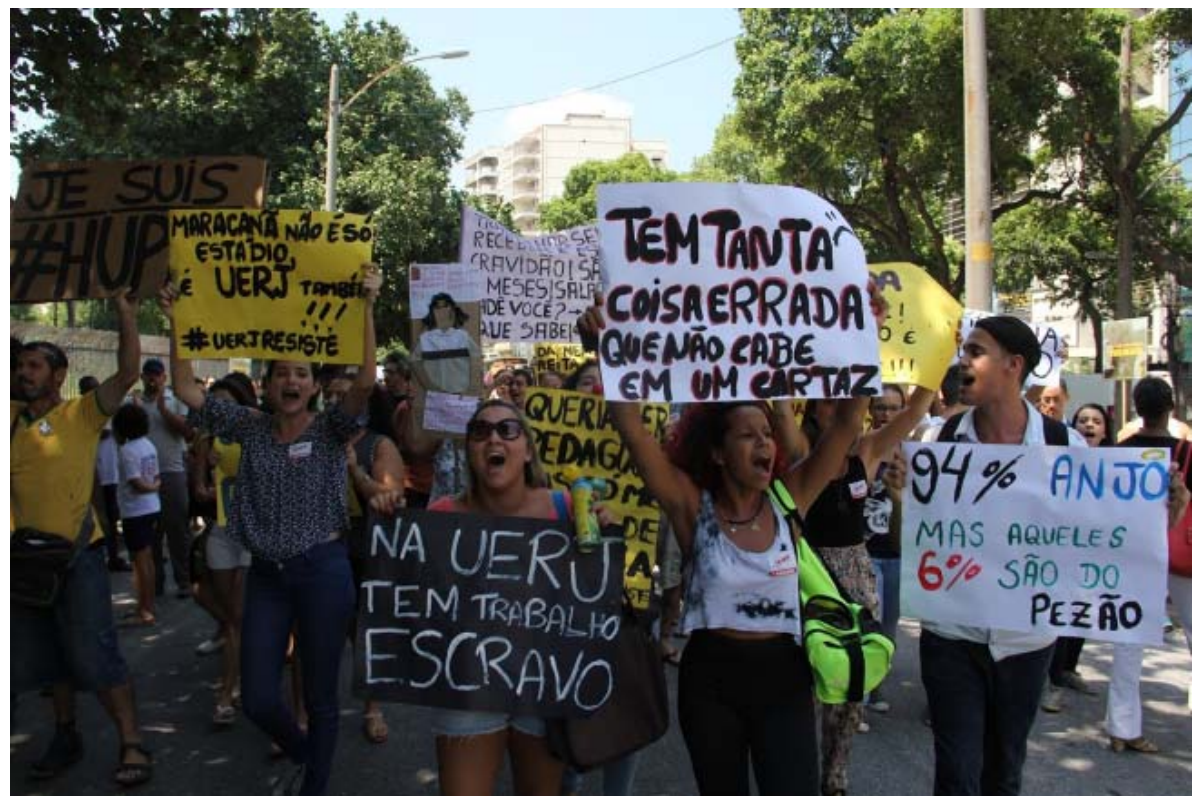

Estudantes protagonizam ato público em defesa dos trabalhadores terceirizados da Uerj (Arquivo Asduerj) 


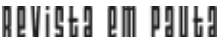

\} A SINISTRA EMERGÊNCIA DO INVISÍVEL - BRAILE, L.; SCHNEIDER, G.; FRANKLIN, S. \}

DOI: $10.12957 /$ REP. 2016.27868

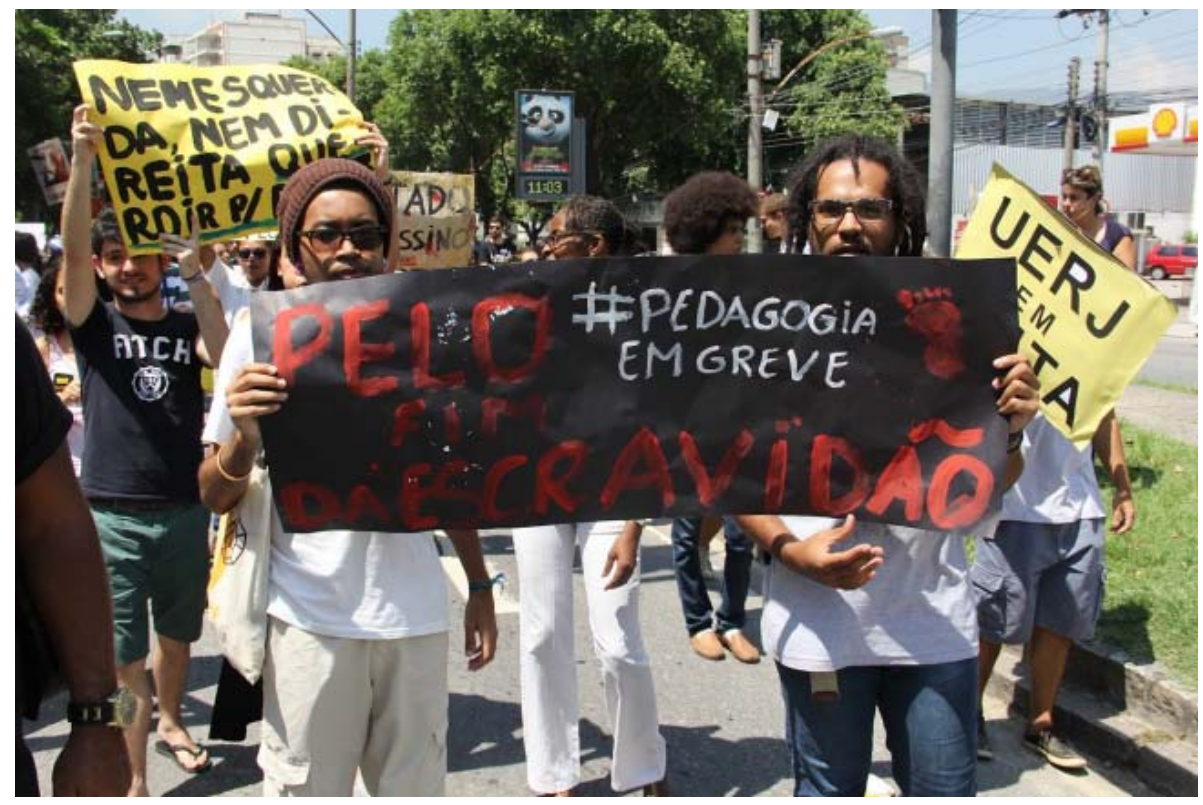

Estudantes do curso de Pedagogia da Uerj em passeata pelo pagamento dos salários dos trabalhadores terceirizados da Uerj (Arquivo Asduerj) 


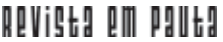

\} A SINISTRA EMERGÊNCIA DO INVISÍVEL - BRAILE, L.; SCHNEIDER, G.; FRANKLIN, S.\}

DOI: 10.12957/REP.2016.27868

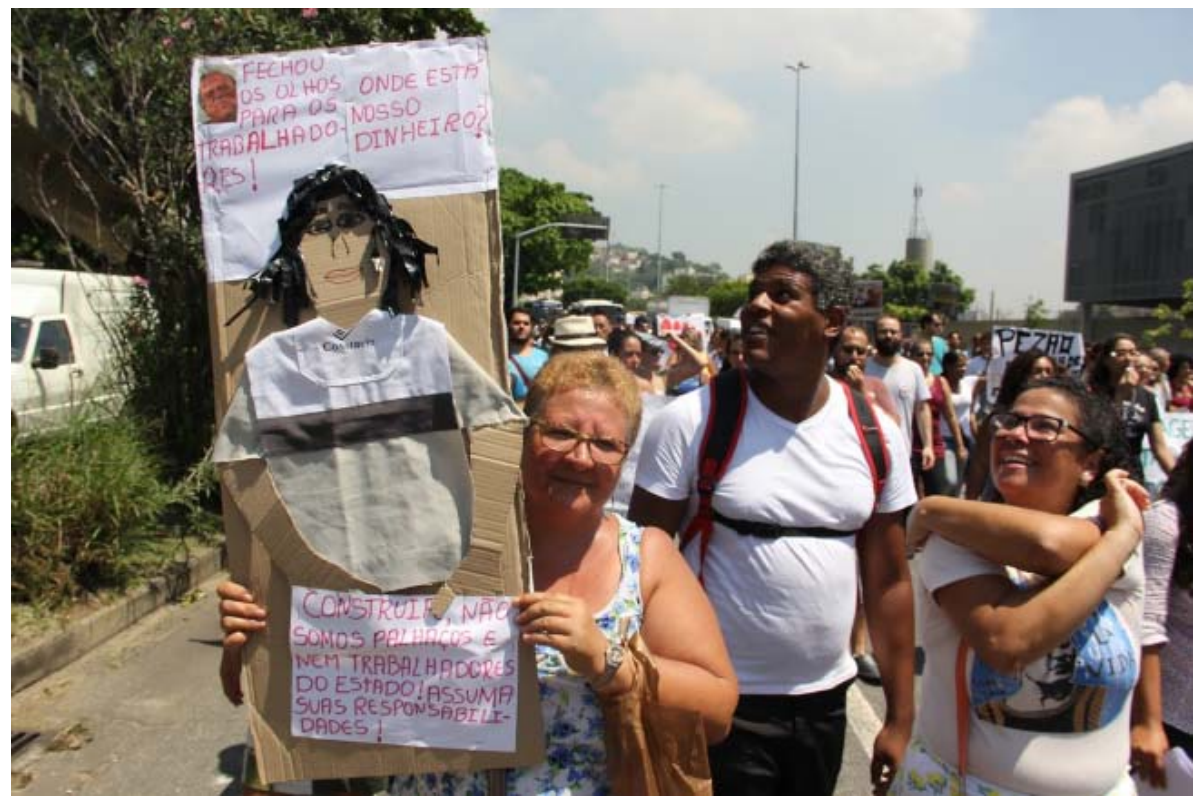

Trabalhadores terceirizados da Uerj protestam contra a empresa Construir, que ficou mais de seis meses sem pagar os seus salários (Arquivo Asduerj) 


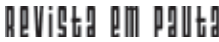

\} A SINISTRA EMERGÊNCIA DO INVISÍVEL - BRAILE, L.; SCHNEIDER, G.; FRANKLIN, S. \}

DOI: $10.12957 /$ REP. 2016.27868

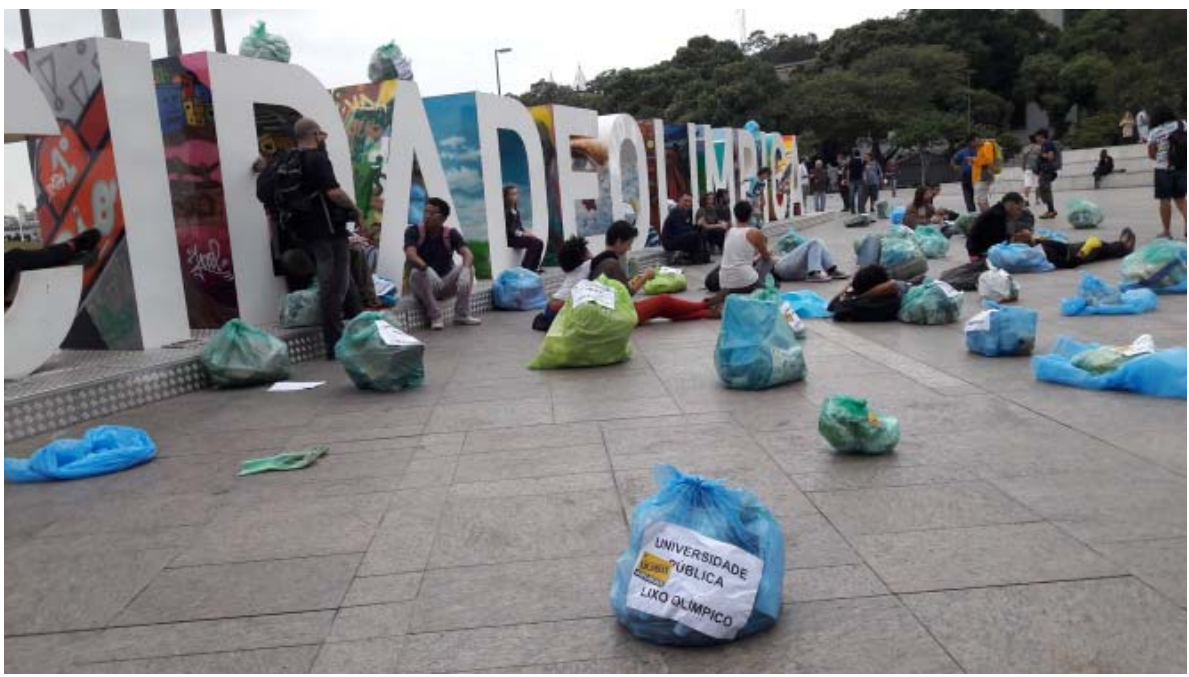

Durante as Olimpíadas, trabalhadores e estudantes da Uerj realizaram ato público no Boulevard Olímpico contra a falta de condições de funcionamento da universidade (Arquivo Asduerj) 


\section{Revigta dII pallt}

\} A SINISTRA EMERGÊNCIA DO INVISÍIVEL - BRAILE, L.; SCHNEIDER, G.; FRANKLIN, S. \}

DOI: $10.12957 /$ REP.2016.27868

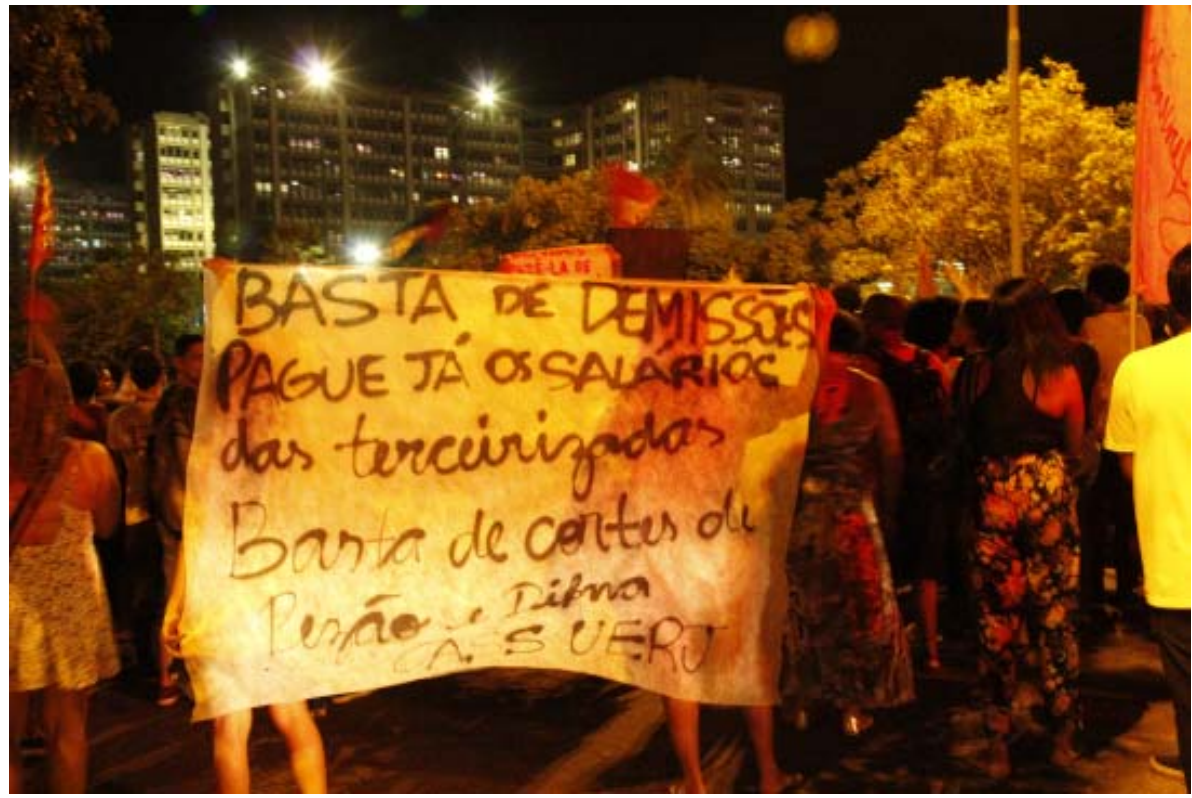

Ato público contra a demissão sumária de trabalhadores terceirizados da Uerj (Arquivo Asduerj) 


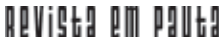

\} A SINISTRA EMERGÊNCIA DO INVISÍVEL - BRAILE, L.; SCHNEIDER, G.; FRANKLIN, S.\}

DOI: $10.12957 /$ REP. 2016.27868

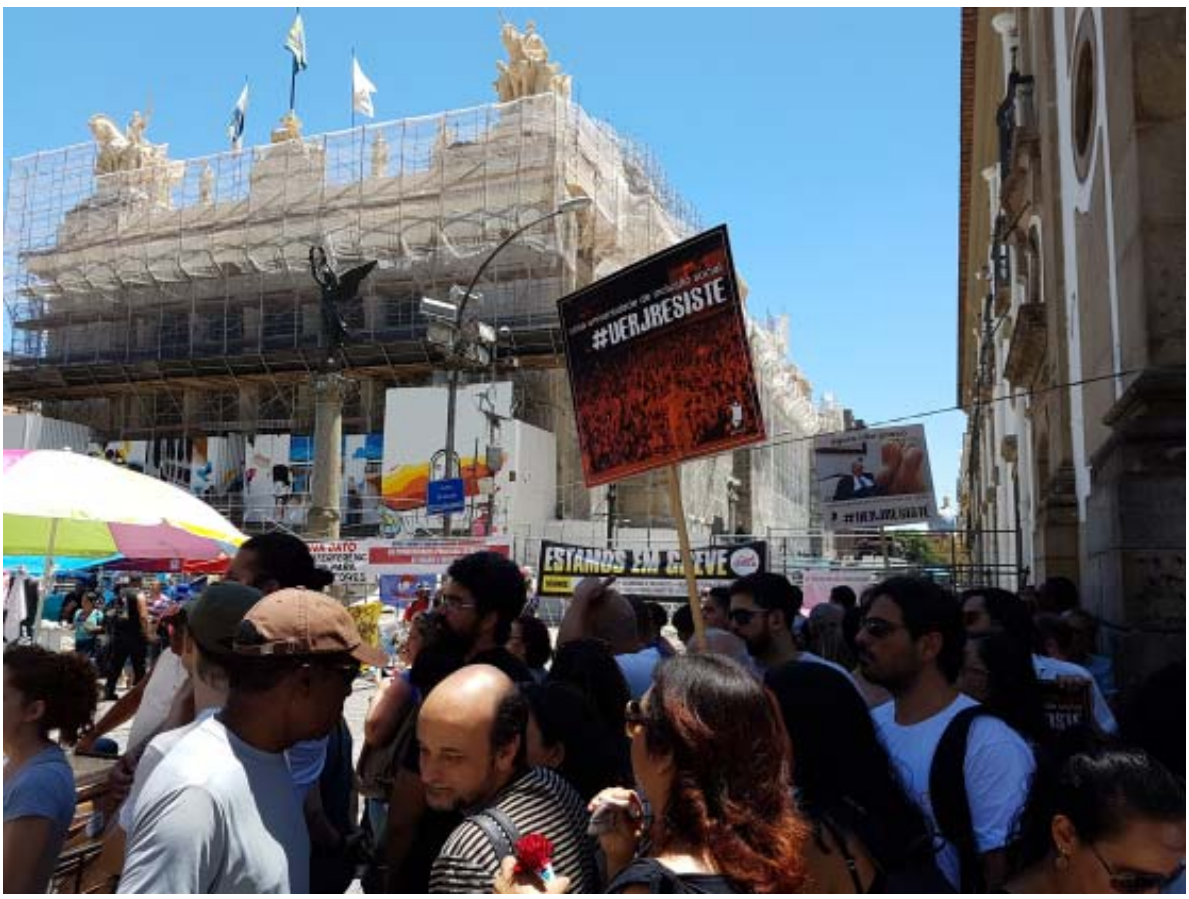

Servidores e estudantes da Uerj participam, em conjunto com outros segmentos do serviço público, de manifestação em frente à Assembleia Legislativa contra os desdobramentos da crise no estado lesivos aos trabalhadores (Arquivo Asduerj) 


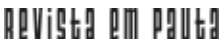

\} A SINISTRA EMERGÊNCIA DO INVISÍIVEL - BRAILE, L.; SCHNEIDER, G.; FRANKLIN, S. \}

DOI: $10.12957 /$ REP.2016.27868

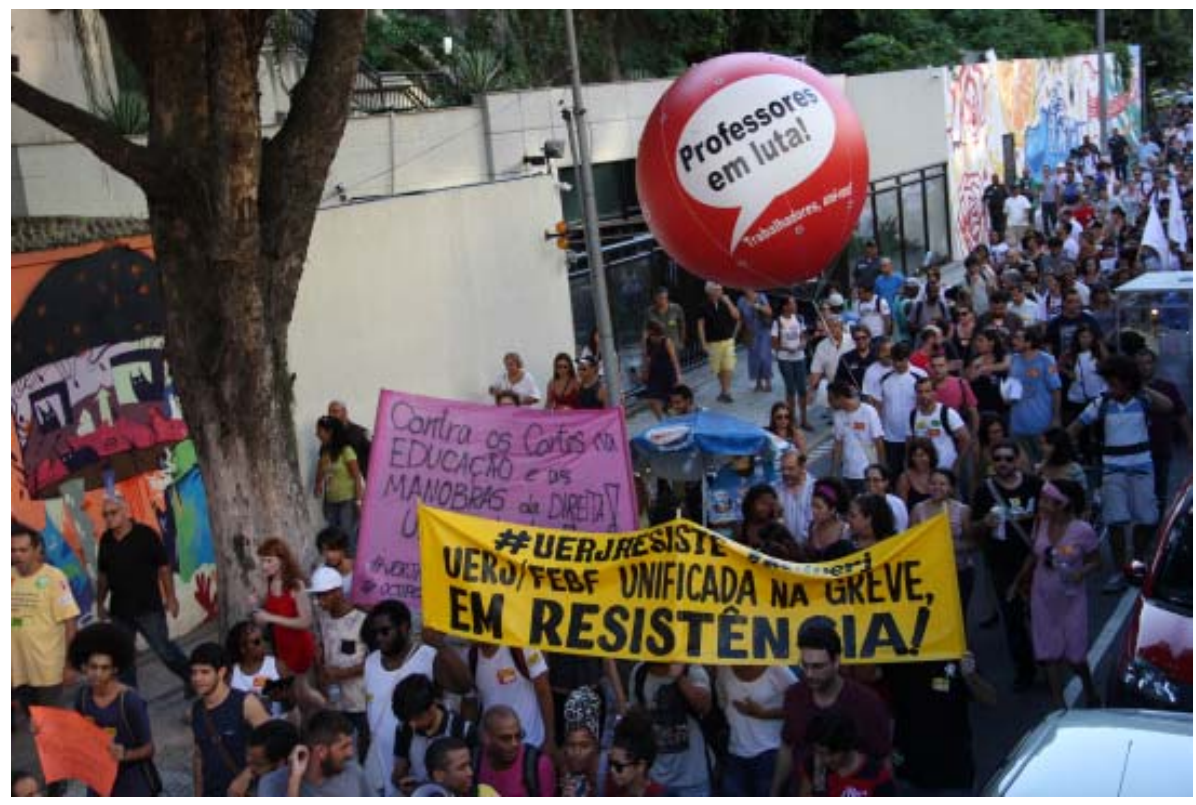

Comunidade universitária da Faculdade de Educação da Baixada Fluminense - FEBF/ UERJ - participa de passeata em defesa da educação pública (Arquivo Asduerj) 


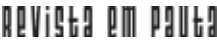

\} A SINISTRA EMERGÊNCIA DO INVISÍVEL - BRAILE, L.; SCHNEIDER, G.; FRANKLIN, S. \}

DOI: $10.12957 /$ REP. 2016.27868

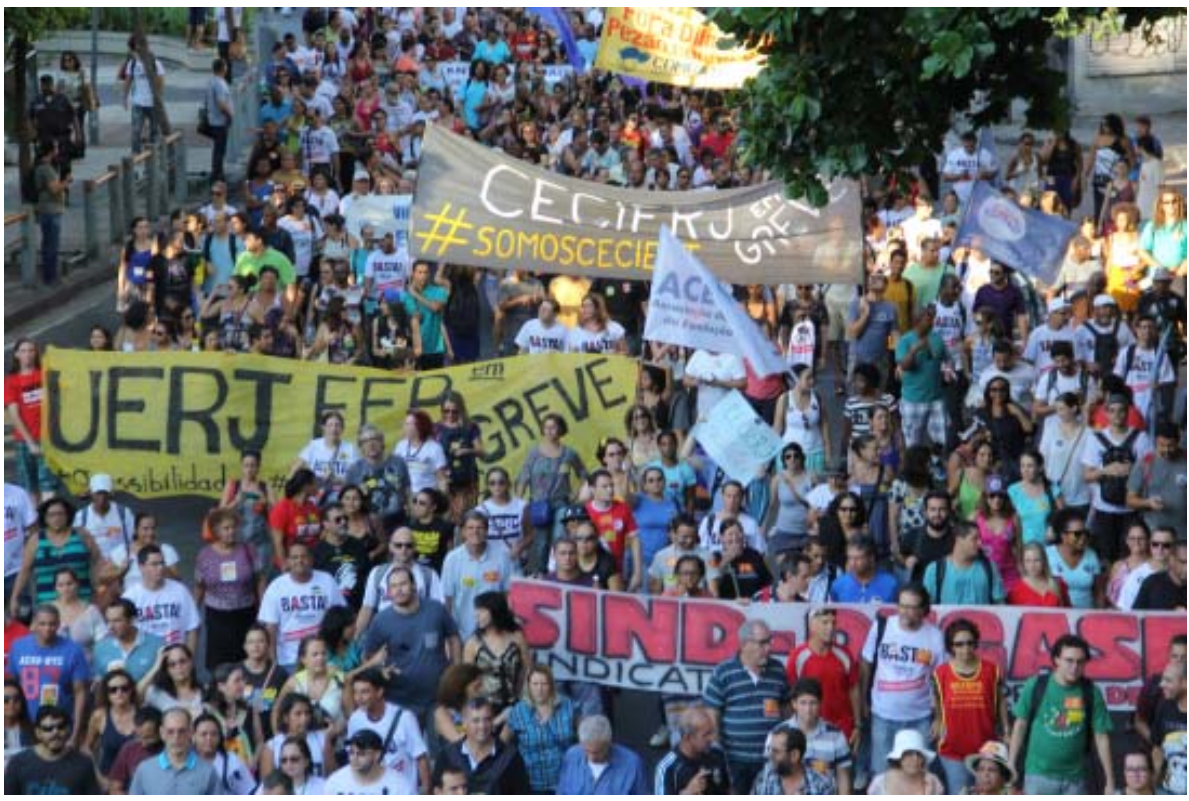

Comunidade universitária da Faculdade de Formação de Professores - FFP/UERJ participa de passeata em defesa da educação pública (Arquivo Asduerj) 


\section{Revigta dII pallt}

\} A SINISTRA EMERGÊNCIA DO INVISÍIVEL - BRAILE, L.; SCHNEIDER, G.; FRANKLIN, S. \}

DOI: $10.12957 /$ REP.2016.27868

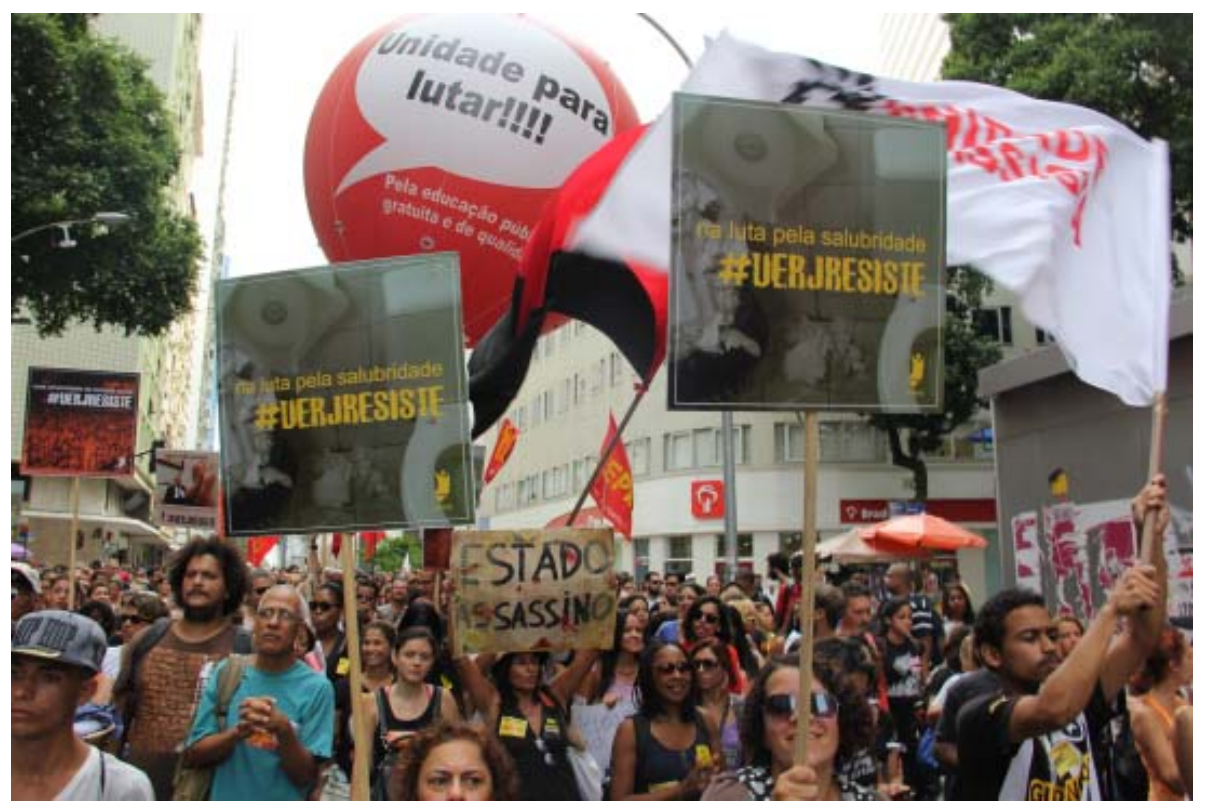

Durante manifestação do serviço público estadual, servidores da Uerj denunciam a falta de salubridade nas dependências dos campi da universidade (Arquivo Asduerj) 


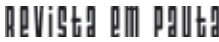

\} A SINISTRA EMERGÊNCIA DO INVISÍVEL - BRAILE, L.; SCHNEIDER, G.; FRANKLIN, S. \}

DOI: 10.12957/REP.2016.27868

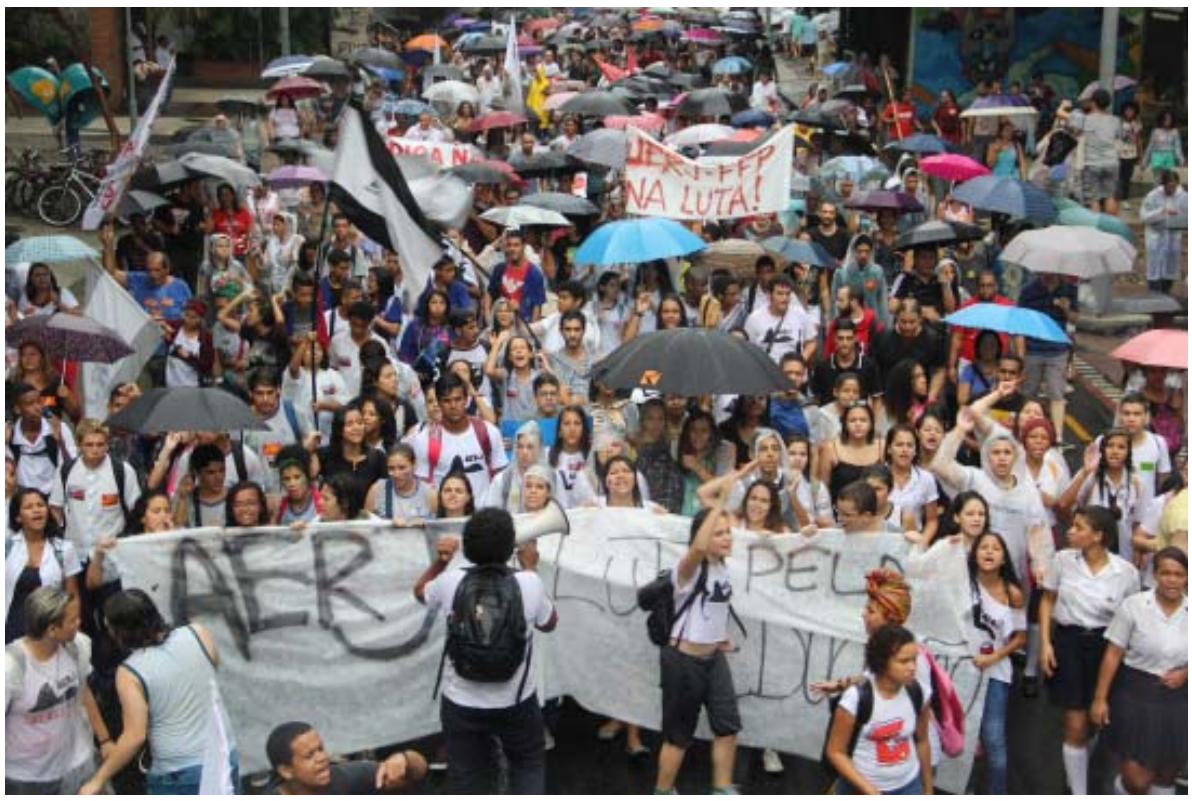

Estudantes secundaristas participam de manifestação em defesa da educação pública (Arquivo Asduerj) 


\section{Revigta dII pallt}

\} A SINISTRA EMERGÊNCIA DO INVISÍIVEL - BRAILE, L.; SCHNEIDER, G.; FRANKLIN, S. \}

DOI: $10.12957 /$ REP.2016.27868

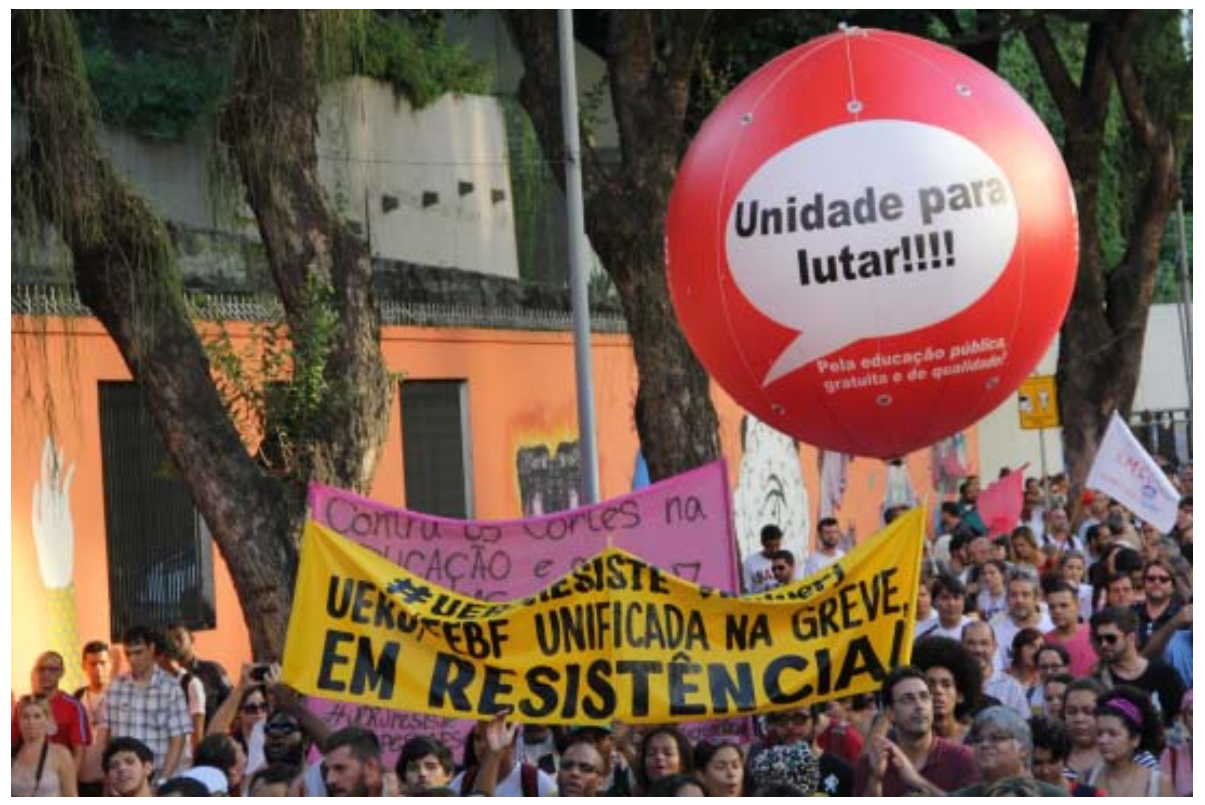

Trabalhadores e estudantes da Uerj participam de manifestação em defesa da educação pública (Arquivo Asduerj) 


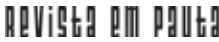

\} A SINISTRA EMERGÊNCIA DO INVISÍVEL - BRAILE, L.; SCHNEIDER, G.; FRANKLIN, S. \}

DOI: $10.12957 /$ REP. 2016.27868

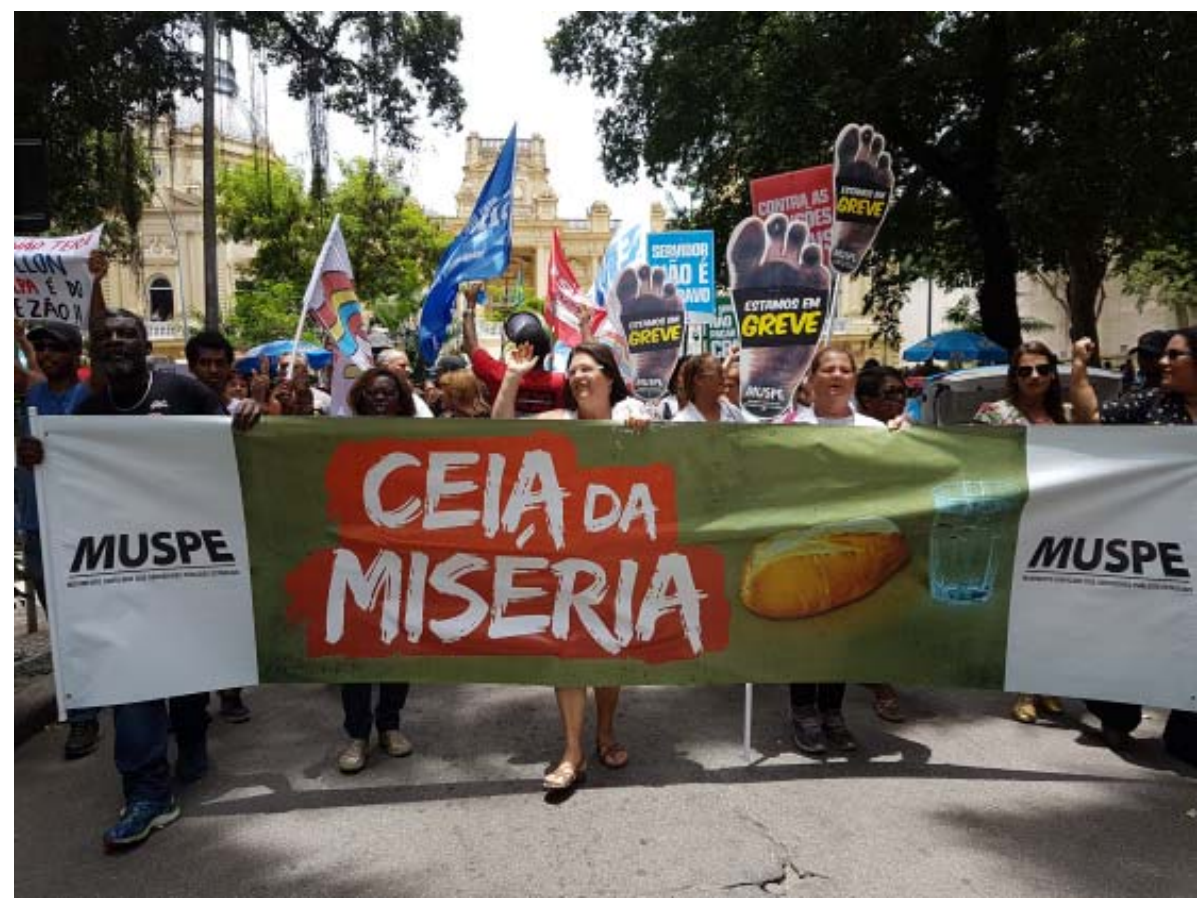

Movimento Unificado dos Trabalhadores Públicos Estaduais (MUSPE) realiza ato público (Ceia da Miséria) no Palácio Guanabara (Arquivo Asduerj) 


\section{Revigta dII pallt}

\} A SINISTRA EMERGÊNCIA DO INVISÍIVEL - BRAILE, L.; SCHNEIDER, G.; FRANKLIN, S. \}

DOI: $10.12957 /$ REP.2016.27868

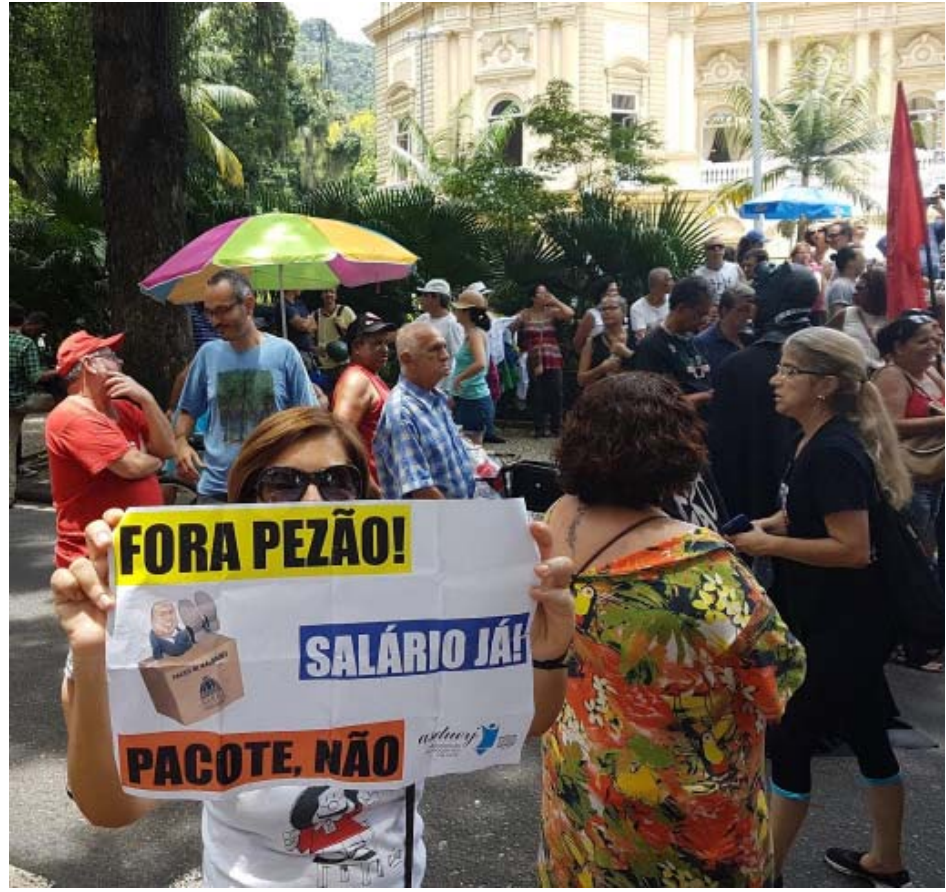

Ato público realizado no Palácio Guanabara contra o "pacote de maldades" anunciado pelo Governo do Estado do Rio de Janeiro (Arquivo Asduerj) 


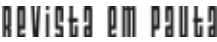

\} A SINISTRA EMERGÊNCIA DO INVISÍVEL - BRAILE, L.; SCHNEIDER, G.; FRANKLIN, S.\}

DOI: 10.12957/REP.2016.27868

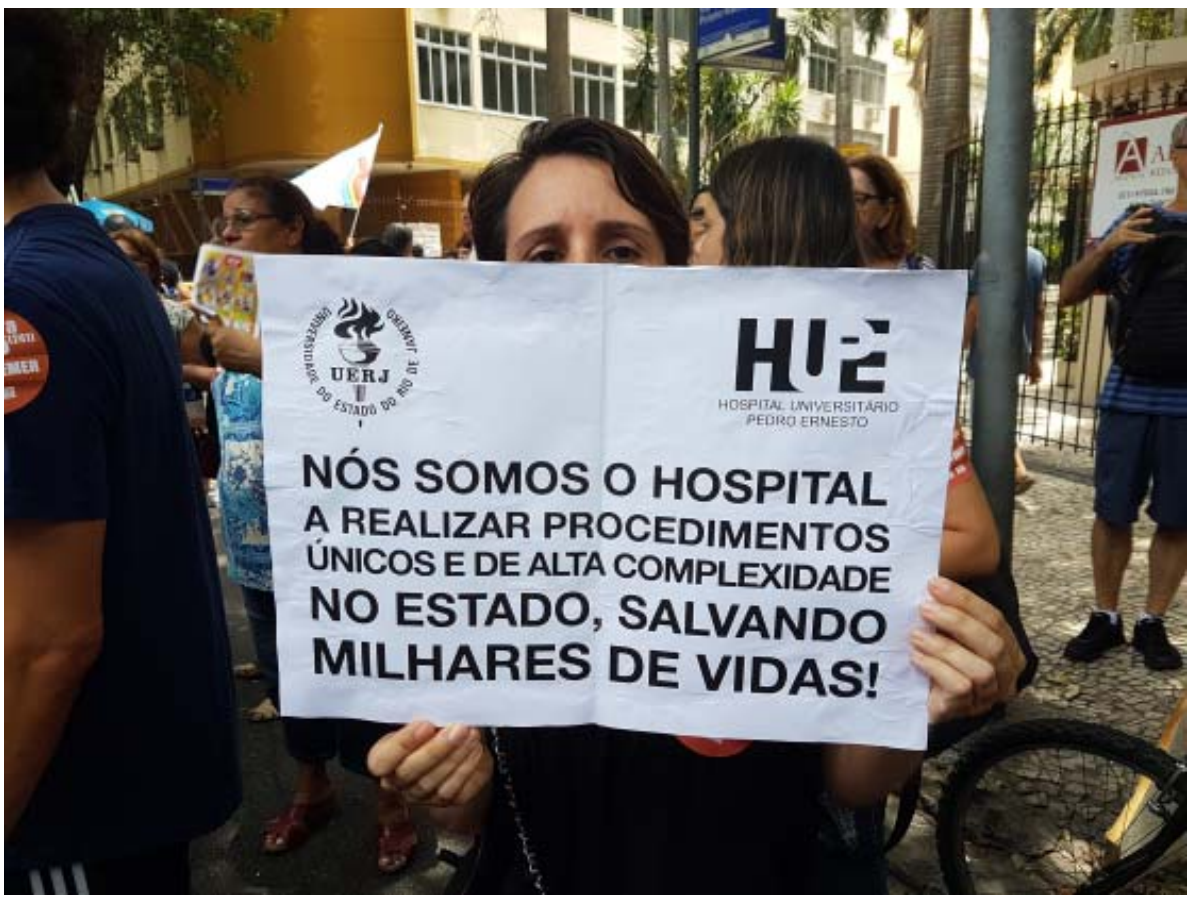

Servidores, estudantes e trabalhadores terceirizados do Hospital Universitário Pedro Ernesto (HUPE-UERJ) se somam à luta geral em defesa da educação pública (Arquivo Asduerj) 


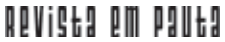

\} A SINISTRA EMERGÊNCIA DO INVISÍIVEL - BRAILE, L.; SCHNEIDER, G.; FRANKLIN, S. \}

DOI: $10.12957 /$ REP.2016.27868

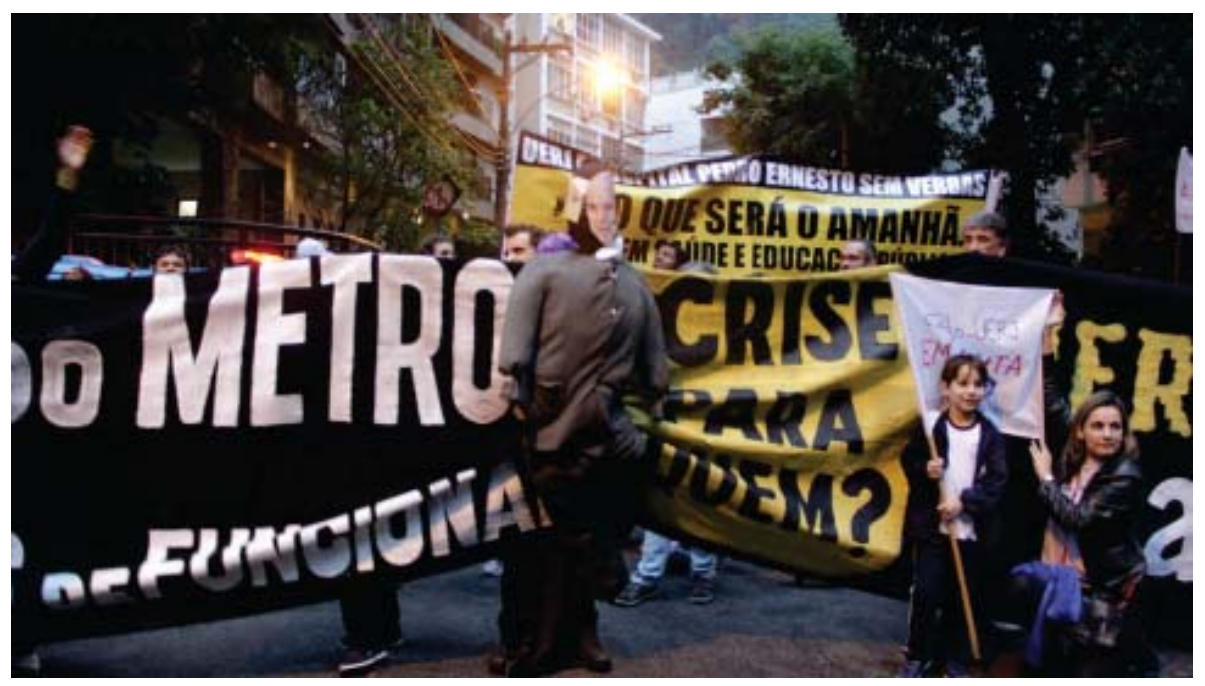

Servidores, estudantes e trabalhadores terceirizados do Hospital Universitário Pedro Ernesto (HUPE-UERJ) e do Colégio de Aplicação da Uerj se somam à luta geral em defesa da educação pública (Arquivo Asduerj)

DOI: $10.12957 /$ rep.2016.27868

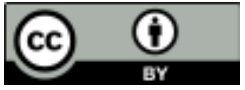

A Revista Em Pauta: Teoria Social e Realidade Contemporânea está licenciada com uma Licença Creative Commons Atribuição 4.0 Internacional. 